Avertin is provided in a concentrated solution with amylene hydrate-1 gram in $1 \mathrm{c.cm}$. The dose works out at between 6 and 8 grams. The appropriate amount of the solution is measured out and enough distilled water to make a $2 \frac{1}{2}$ or 3 per cent. solution is lieated to $38^{\circ} \mathrm{C}$. The avertin is then added and the mixture is shaken till a clear solution results. The most important points are that the temperature must never exceed $40^{\circ} \mathrm{C}$. and that the final solution must be free from hydrobromic acid and therefore free from dibromacetaldehyde; $5 \mathrm{c.cm}$. of the dilute solution are taken and a drop of 1 in 1,000 Congo red solution is added. The cotour should remain bright orange red. The blue reaction of free acid is sometimes delayed and it is essential to make the test immediately before administration.

The solution being now ready and satisfactory, it is injected into the rectum fairly slowly through a catheter and funnel. The catheter must be passed well into the rectum proper. The patient is best arranged lying on the left side with a pillow under the pelvis. The 250 or $350 \mathrm{c.cm}$. of solution are easily retained if the injection takes three or four minutes. Attempts have been made to give fractional doses, running in more solution if the anaesthesia produced by the original dose was inadequate. It has been shown that the arertin in solution is more readily absorbed than the water. This makes all calculations with regard to strength of solution useless, and it is impossible to gauge rate of absorption or to prophesy the depth of anaesthesia. which will be obtained. If undue lepth should be observed at an early stage, wasing out the rectum for the purpose of removing any of the avertin that may remain there is a sound proceeding.

In practice, it seems best to give the rectal injection thirty minutes before the advertised time of the operation. This means that the patient need not be disturbed for twenty minutes, and then may be taken straight to the theatie. During the induction period we have endeavoured to keep the patient quiet, to keep the room dark, and to keep out all sources of irritation. Flessa, however, says that some patients resent strongly the sepulchral atmosphere, and that light and noise have no effect upon the induction, so that it is better to allow the ordinary ncise and disturbances to go on normally. 6

Having taken the patient to the theatre, the anaesthetist tests the skin reflexes, and either starts the inhalation anaesthetic at once or, if a fairly deep state has been achieved, withbolds the ether till necessars. Ether, C.E. mixture, chloroform, gas and oxygen, or local anaesthetic may be used. If gas and oxygen be used, one has to wait for a severe stimulus to be given by the surgeon before the patient will breathe sufficiently deeply to take in enough of the gases. The amount of ether and chloroform used will be measured in drachms rather than in ounces. Once a sufficient relaxation has been obtained, it is often unnecessary to give any more of the inhalant. The peritoneum that has been relaxed enough for the abdomen to be opened will remain so for closing, unless the operation lasts so long that the avertin effect is wearing off. The usual duration of the narcosis is from one and a half to two hours from the time of the injection. About four hours from the start the patient is usually quite conscious of his surroundings.

The chief care in the nursing is watching the relaxed jaw and tongue; this applies during the period of induction as well as of recovery. A rectal washout used to be given on return to the ward. This is now considered to be unnecessary. Should the patient's condition demand it the routine saline treatment is carried out.

In only one case have I scen any trouble directly due to an avertin anaesthesia. In this case, which was reported in the Lancet ${ }^{7}$ by Sir Francis Shipway and Dr. Blomfield, the patient died twenty hours after the administration of a dose at the rate of 0.125 gram per kilo. It would seem probable that in that case a deficiency of thyroid secretion had diminished the paticnt's power of detoxicating and eliminating the drug.

The lines of treatment in cases of prolonged delay in return to consciousness are respiratory stimulation by injections of lobeline, the giving of carbon dioxide and oxygen mixture, and injections of ephedrine to maintain the circulation. So far as I can discover, thyroxin has not been tried; but this would seem a rational method of assisting elimination.

In conclusion, avertin can be used to provide a deep narcosis, which is casily convertible into an anaesthesia by the giving of very small quantities of the ordinary anaesthetics. It is reasonably safe in doses up to $0.1 \mathrm{gram}$ per kilo of body weight. It eliminates nearly all the mental stress which accompanies the usual administration of an anaesthetic. It has no effect upon the respiratory tract. It is well taken by persons with excessive thyroid secretion. It is fairly easy to give.

On the other hand, it is not controllable and cannot safely be used as the sole anaesthetic agent. It has to be prepared with care. It should not be used where there is any disease of the kidneys, liver, or colon, or where there is thyroid deficiency. It is not, as was at first hoped, an anaesthetic that anybody can give at any time. It requires an experienced anaesthetist to control the superimposed anaesthesia. The necessity of giving the injection half an hour beforchand adds to the anaesthetist's duties and makes its use diffcult in hospital practice where cascs follow each other with rapidity.

In certain cases and types of patients avertin is a great help. As a routine anaesthetic agent, it is hardly practicable.

1 Klin. Woch. 1928, No. 49. ${ }^{2}$ M Müch. med. Woch., June 7th, 1929.

3 Zentraibl. f. Chir., 1929, No. 19. 4 Miinch. med. Woch., June 7th, 1929.
5 Zentralbl. f. Chir., 1929, No. 19. 6 Münch. med. Woch., June 7th, 1929.
; 1929, vol. i, p. 546.

5 Zentralbl. f. Chir., 1929, No. 19. 6 Münch. med. Woch., June 7th, 1929.

\section{THE TREATIENT OF TORTICOLLIS.*}

\section{BY}

B. WHITCHURCH HOWELL, F.R.C.S.ENG.,

SURGEON TO THE QUEEN'S HOSPITAL FOR CHILDREN, LONDON; SURGEON TO THE BROOKFIELD ORTHOPAEDIC HOSPITAL; ORTHOPAEDIC SURGEON TO THE ESSEX COUNTY COUNCIL.

TonticolnIs or wry-neck is a very rare deformity, occurring once in every 150,000 births. Congenital club-foot is ten times as frequent. The outstanding deformity is the tilting of the head towards the affected side, with rotation of the chin forward and away from the affected side. Secondary deformities are facial asymmetry and scoliosis, chiefly of the cervical region.

The cause of the deformity is contraction of the sternnmastoid muscle, more particularly its sternal head. Its origin is either congenital or acquired, the following being the chief varieties:

A. Congenital.-(1) Prenatal; (2) natal.

B. Acquired.-(1) Rheumatic; (2) reflex-for example, tubercle of cervical spine; (3) ocular; (4) spasmodic, etc.

The congenital variety, as indicated abore, has two subdivisions-prenatal and natal-and there are several theories as to their origin.

1. Prenatal.-The prenatal subdivision inclucles those due to abnormal posture in utero, giving rise, on the one hand, to temporary or permanent shortening of the sterno-mastoid, or, on the other, to localized fibrosis and contracture of the muscle from interference with the blood supply-thus being allied to Volkmann's ischaemic paralysis. The rarer forms are due to abnormal development of the cervical vertebrae, which may be unusual in number and often wedged. A certain percentage of the latter are associated with Sprengel's shoulder or congenital eleration of the shoulder. In addition, cervical ribs may be present. The contracture of the sterno-mastoid is usually on the right side, and is very rarely bilateral. I have personal records of three cases of bilateral torticollis, each one of which was associated with congenital abnormalities of -the cervical spine, whilst in one Sprengel's deformity was present.

2. Natal.-The natal subdivision of the congenital varicty is generally associated with a difficult confinement. The presentation is usually a breech, when there may

* A paper read in the Section of Orthopaedies at the Annual Mecting of the British Medical Association at Manchester on July 25th. This was illustrated by photographs of patieñts before, during, and after treat ment. Photographs of the operation table used are reproduced at page 721 . 
be trauma of the after-coming head and neck, resulting in rupture of fibres of the sterno-mastoid, with or without the formation of a haematoma within its sheath. Bruising of the neck is not always present, however, and in these instances the so-called haematoma is found generally in the middle and lower third of the substance of the muscle. From such examples arose the theory of the congenital origin of the deformity-that it is due to intramuscular fibrosis during intrauterine life. This theory is borne out by anatomical experiments which show that the blood supply of the lower half of the muscle is more easily interfered with by torsion of the neck in utero, thereby causing ischaemia of that part. On the other hand, I have had instances of torticollis associated with Erb's paralysis on the same side, thus supporting the traumatic theory of the cause of the deformity. In one instance there was a history of heredity, the mother of the patient also suffering from torticollis. With regard to sex incidence, females were definitely in the majority.

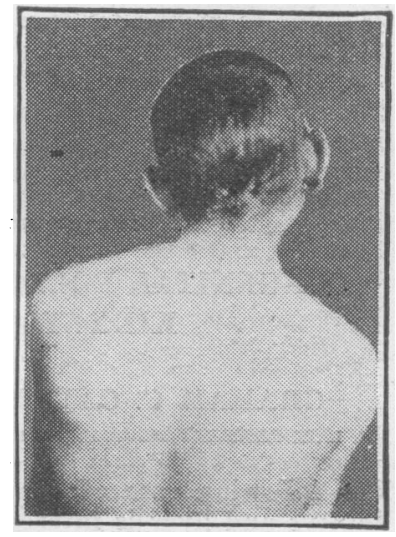

Before treatment.
In this paper I do not propose to discuss the acquired varieties of torticollis, the differential diagnosis of which can be made by a careful clinical examination of the patient, in particular of the eyes, the spine, and the $x$-rav films, after which the appropriate line of treatment can be carried out.

\section{Treatment of Congenital Torticollis.}

This depends upon the age at which the patient is brought to the orthopaedic surgeon. The earlier the better, as a complete cure within a few months can then be promised.

\section{Early Cases}

If the child be brought within a few days of birth then the cure is simple, non-operative, and should be complete within three months. To secure this the orthopaedic

\section{Late Cases.}

These have marked shortening of the sterno-mastoid, with or without facial asymmetry and scoliosis. In all such patients operation, followed by suitable exercises and reeducation, is the only cure. I have operated upon 24 cases, of which 23 were of the true congenital variety. The only acquired type was a case of spasmodic torticollis in a woman, in whom the condition had existed for a considerable number of years. The operation in this particular

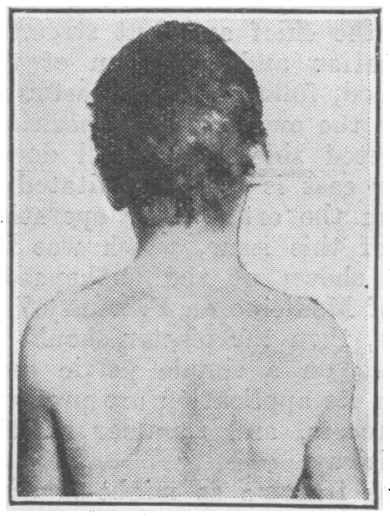

After treatment. and thereby paralysing for some months, the muscular branches of the spinal accessory nerve which supply the sterno - mastoid, with complete relief for a considerable time.

Of the 23 cases of true congenital torticollis all except 3 were operated upon by the subcutaneous method, the sternal end of the muscle being divided with a blunt Jones tenotome. Of the 3 cases treated by the open division of the sternomastoid, 2 were tackled at the lower end, and ono at the upjer end below the mastoid process. This latter case occurred in a girl, and was the only casc in which an incomplete cure resulted from the subcutaneous division of the sternal end. Open division of the upper end resulted in a complete cure, the operation scar being hidden by the hair.

\section{Details of the Subcutaneous Operation.}

The essentials of the operation are extensive preparation of the skin, including both upper limbs; adequate towelling off of the operation area; very skilled assistance, consisting of chief assistant, together with helpers to hold and pull upon the upper limbs; endotracheal anaesthesia whenever possible; adequate airway; maintenance of over-correction of the deformity after tenotomy by a plaster-of-Paris cast, followed by exercise and re-education by an

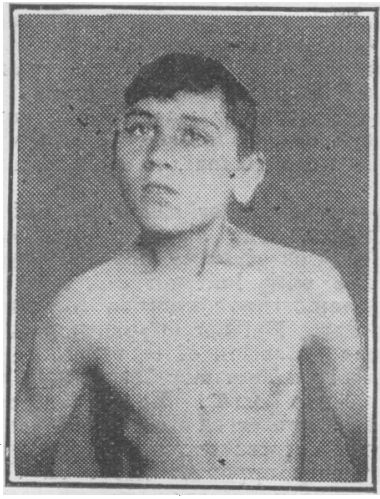

Before treatment.

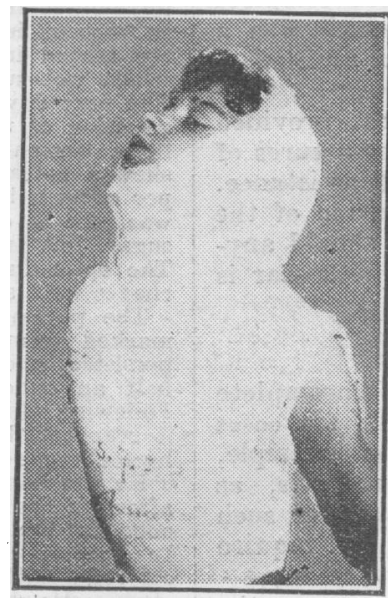

During treatment.

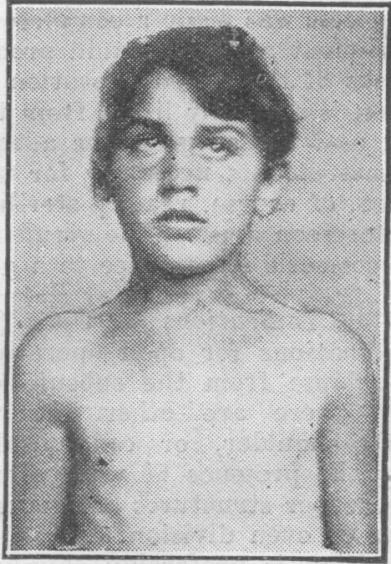

After treatment: masseuse rotates and tilts the head to the position directly the reverse of the deformity, whilst the mother pulls down the shoulder and arm on the side of the deformity. After these movements have been repeated a number of times the masseuse kneads the contracted muscle, especially in the neighbourhood of the so-called haematoma should this exist. The treatment is repeated daily, and in the interrals the mother endeavours to copy the masseuse. Correct posture of the child whilst being carried can also help in the cure. Just as a mother can cause scoliosis in her infant by carrying it constantly on the same hip, so can she, by reversing the process, cure that deformity, Exactly the same simple method can be applied by the mother to the cure of torticollis. orthopaedic masseuse after its removal some weeks after the operation.

The patient having been anaesthetized, a flat sandbag is placed transversely beneath the shoulders, the head held well over the end of the table, the skin prepared, and the towels applied. Each upper limb is held adducted by the hand by assistantis, whilst the chief assistant takes sole charge of the head, and moves it as required by the surgeon during the operation. He is seated on a stool, with the table so arranged that he can-hyperextend the head. The head is flexed to relax the sternal end of the muscle, and the skin is picked up with toothed dissecting forceps, held in the left hand, about an inch above the clavicle close to the sternal end. This facilitates the 
introduction of the tenotome beneath the skin. The forceps being dispensed with, the finger and thumb of the left hand firmly grip the sternal portion of the muscle and lift it away from the deep structures of the neck. The tenotome is then slid transversely behind the tendon from the inner side, and a moderate degree of tension put upon it by traction on the head by the chief assistant, a similar amount of traction being applied at the same time to the upper limb on the affected side. The tendon is thus cut through slowly and the tenotome withdrawn. The surgeon then kneads the muscle, especially the clavicular portion, whilst the chief assistant stretches the contracted tissues by rotation and extension of the head. A dressing is now applied, followed by a plaster-ofParis jacket, with the head in the over-corrected position, and the shoulder on the affected side pulled well down. The application of the plaster cast is much facilitated if the operation be performed on the orthopaedic operation table described at page 721 of this issue, which was inrented some rears ago, and shown at the Orthopacdic Section of the Royal Society of Medicine on February 7th, 1928. If this be not arailible, then the plaster should be applied with the patient lying on a simple pelvic rest. The points to be enphasized in its application are pressurc beneath the chin, mastoid process, and shoulder on the affected side, and adequate airway.

The plaster jacket is not as irksome as might appear patients being able to walk, and even play football and ride a donkey. This is bi-valved in four weeks' time, and exercises and re-education are commenced by the masseuse. At first the exercises should be carried out in the prone position, with the head low to avoid the faintness sonetimes experienced on removal of the jacket. It is worn as a corrective splint for another four weeks, and then it is discarded. A complete cure usually results in three to six months, depending on the degree of deformity present per se, as well as the secondary ones; naturally the facial asymmetry takes longest to disippicar.

It should be emphasized that the masseuse undertaking the treatment should make the acquaintance of the patient some dars before the operation in order to initiate the corrective exercises which will be necessary afterwards, and should, of course, be present at the operation.

\section{Results of Operation.}

The resilts of operation by this method were complete cures in 19 out of 20 cases; the one case which was a partial success was made a complete one by open division of the attachment at the mastoid process.

The risks of the closed operation are not great provided the tendon is carefully lifted from the deeper structures of the neck and the surgeon has adequate skilled assistance. All the instruments necessary for the open division of the tendon are, of course, readily sterilized for use should anything unforeseen arise. The resulting fine pinprick scar is of great cosmetic importance to a girl.

Indications for Open Operation.

The indications for open operation are: (1) incomplete cure or relapse from the subcutaneous method; (2) cases in which there are other abnormalities-for example, Sprengel's shoulder, or congenital cervical scoliosis, ats shown by the presence of wedged vertebrae, etc. In such cases the deeper structures are contracted, and will require stretching or even division.

The incision is preferably obliquely transverse over the sternal end of the clavicle to make the scar as inconspicuous as possible, the platrsma is divided, and then the sternal head of the muscle over an elcrator. The clavicular head seldom gives trouble, exccit in those instances where a previous operation may have caused fibrous tissue formation. The head is then stretched to the over-corrected position, the soft tissues carefully sewn up with fine catgut, and the skin with fine salmon gut, and a plaster jacket applied. The resulting scar is disfiguring, and tends to broaden as years go by.

Contraindications for Operation.

1. Those cases in which $x$-ray films show a marked congenital bony deformity, generally due to wedged vertebrae, with perhaps cervical ribs.
2. Bilateral torticollis I have seen three such cases.

3. Those cases in which the torticollis is secondary to clisease of the spine-for example, tubercle.

In all the above, where bony deformity is present, it would be of little value to divide the contracted soft structures, as the bony ones would remain, and these are not correctable.

Summary.

This paper has been written, and these photographs of cases before, during, and after treatment have been shown, in order to emphasize that torticollis may be prevented hy careful ante-natal examination of the mother to secure the simplest presentation, avoiding natal injury. Further, the younger the infant the sooner the cure. Lastly, the subcutaneous tenotomy of the sterno-mastoid muscle gives a complete, lasting, scarless result.

\section{CONGENITAL POLYCYSTIC DISEASE OF 'I HE KIDNEYS AND LIVER.}

\author{
BY
}

GRAHAM C. CAMPBELL, M.R.C.S., L.R.C.P.,

LATE RESIDENT MEDICAL OFFICER, ROYAL UNITED HOSPITAL, BATH.

THE following case of - congenital polycystic disease of the kidneys and liver is interesting not only on account of the pathological condition of the liver, but also because of the family history. As happens in so many similar cases, the condition of the kidneys and liver was only discovered at post-mortem examination: during the lifetime of the patient it had never been considered in the differential diagnosis of his illness.

History.

A. H., a male aged 55, saw his family doctor in February, 1929 He had been sent by his wife because of occasional vomiting, fron which he had suffered during the preceding fortnight. His own mental outlook was curious, in that he seemed quite unconscions of the fact that he was ill. At that time he was very anacmic: his tongue was pale and flabby, but there was no glossitis. liv liver was slightly palpable in the right hypochondrium. The illness was was slighty palpable in the right hypochondrium. The illess was diagnosed as Addison's anaemia, and he was ordered to rest Following the adoption of this treatment, especially after taking the liver, he vomited several times, and the administration o liver was therefore stopped. Two days later he had a copious bright red hasmorrhage from the rectum; rectal examination revealed no abnormality. He was given kalzana tablets and an intramuscular injection of $4 \mathrm{c.cm}$. of thromboplastin, but this anc subsequent injections of the same drug had no effect. Following the second injection he had hacmorrhage from the right nosiril, which was successfully plugged with gauze soaked in adrenaline. which was successfully plugged with gauze soaked in adrenaline. The next day blecding occurred from a small denuded area in the situation of the lower left canine tooth; this was finally arrested
by a turpentine application. A blood count made at this time showed marked diminution in the number of red cells $2,500,000$ per c.mm.), but no obvious change in the white count. The urine was pale in colour; its specific gravity was 1010; it contained no sugar, but traces of albumin and an occasional cast were found. The optic discs though pale were normal, and no retinal haemorrhages were seen.

'The patient now began to be rather sleepless, and there was marked tremor of the fingers. The bleeding from the rectum persisted, and to check it he was given by mouth an emulsion of half an ounce of turpentine with half an ounce of castor oil. Following this treatment haemorrhage stopped for one day, but it reappeared on the next day. Neither suppression of urinc nor hacmaturia followed the administration of turpentine.

He was admitted to hospital on February 16 th, about a fortnight after his first visit to his private doctor. He complained of a dull ache in the right loin, and preferred to lie on his left side. In hospital he was given an intravenous injection of calcium chloride, without, however, any apparent effect on the hacmorrhage. He died on February 18th.

\section{Post-mortcm Findings.}

Kidncys.-Both kidneys were equally enlarged and cyslic; each weighed $2 \mathrm{lb}$. and measured $6 \frac{7}{3}$ inches from its upper to lower pole and $3 \frac{3}{4}$ inches in breadth. The cysts varied in size from that of a pea to that of a walnut.

Livcr.-The liver was uniformly enlarged, and wcighed $3 \frac{1}{2} \mathrm{lb}$. Its anterior surface measured $6 \frac{3}{8}$ inches by $6^{3}$ inches by $7 \frac{3}{4}$ inches. Its anterior surface measured 18 ince was thickly studded with small cysts, the size Its whole substance was thickly studded with
of which varied up to that of a hazel nut.

Other Organs.-No cysts were seen in the pancreas, and no pathological condition was found in any other organ.

Microscopical Examination.

The scetion of liver examined microscopically showed typical congenital cysts. Normal liver tissue was seen, between which were spaces lined with a flattened epithelium. The normal tissue was not compressed, and the cysts probably arose from ordinary was not compressed, and the cysts probably arose
liver-forming cells very early in their development. 